\author{
Olle ESKILSSON and Gustav HELLDÈN \\ Kristianstad University, Department of Mathematics and Natural Sciences
}

\title{
A LONGITUDINAL STUDY ON 10-12-YEAR-OLDS' CONCEPTIONS OF THE TRANSFORMATIONS OF MATTER
}

\author{
Received 23 August 2002; first revision 20 February 2003; \\ second revision 10 September 2003; accepted 12 September 2003
}

\begin{abstract}
The main aim of this project was to study young people's ability to use science knowledge when talking about and explaining everyday phenomena involving transformations of matter. Students' individual knowledge was studied both as their spontaneous explanations and as their explanations with appropriate help in discussions with the researcher or with other students. The framework for learning in this study was a social constructivist perspective of learning. In the project students discussed everyday phenomena with peers and with the researcher. The role of the discourse was stressed in the interviews as well as the development of students' use of their mental models when explaining everyday phenomena. Data were gathered through four interviews with each one of 40 students, between 10 and 11 years of age. The development of the basic particle model was one of the themes during the instructional units. Other recurrent themes were states of matter, gases and chemical reaction. Most of the students were able to use knowledge of science when talking about known everyday phenomena. Almost all of the students in the group developed the use of their own mental models during the project. [Chem. Educ. Res. Pract.: 2003, 4, 291-304]
\end{abstract}

KEY WORDS: Primary science; everyday phenomena; transformations of matter; states of matter; gases; chemical reactions; mental models; conceptual models; particle model; social context; Vygotsky

\section{FRAMEWORK AND AIMS}

In Swedish primary schools, everyday phenomena are often described but usually not explained. Perhaps children could be helped to use their imagination when building their own models for discussing and explaining phenomena. An elementary particle model of matter is one example of a scientific model that could be a basis for the students' own mental models. A particle model for matter could help students to understand and explain phenomena involving transformations of matter.

The conceptual framework for the study was a social constructivist perspective of learning described by Ernest (1996). Learning involves both individuals' construction of knowledge and social interaction between individuals. Understanding emanates from social interaction and will be interpreted and then made clear for the learner. Vygotsky (1996) described students' ability to learn in cooperation with others with the concept of the zone of proximal development, ZPD. At a certain level of development, an individual can cooperate in special situations. With the new knowledge acquired he/she can cooperate in more advanced situations. Sutton (1996) described learning science in school as managing to use science knowledge when talking about everyday phenomena in a new way. This does not mean that students replace their old structures of thinking with new ones. In some studies, 
where the researchers had the individual's learning as a starting-point, there were some results where the individual learning was not attached to changes of the mental structures. Taber (1998, 2000, 2001), Tytler (1998), Petri and Niedderer (1998), Helldén (1998), and Marton (1998) all meant that students used different models of thinking when talking about everyday phenomena. Solomon (1983) and Leach and Scott (2003) described learning as the students' development of their ability to use new ways of explaining on an individual level, and their reorganisation and reconstruction of the new information on a social level.

According to Leach and Scott (2003), learning science as learning to use science language could be understood as a process of internalisation. The learner must interpret, reorganise, and reconstruct his/her experiences from the interaction with others. Leach and Scott put learning in a social context together with learning as an individual activity. Sfard (1998) described learning by means of two metaphors, the acquisition metaphor and the participation metaphor. She meant that teaching must be an appropriate combination of these two metaphors, appropriate for the students and the teacher.

When children learn a science concept meaningfully, they build mental models of it, just as scientists do. When Glynn and Duit (1995) discussed constructing conceptual models, they made a distinction between conceptual models and mental models. Modelling is the process of constructing models and is a mental activity of an individual or a group. Glynn and Duit meant that students' mental models refer to their personal knowledge, whereas conceptual models refer to scientifically accepted knowledge. In addition, conceptual models were described as tools for teaching/understanding physical and natural systems, while mental models were what people really had in their heads. Students' mental models are different from the conceptual models of science. Therefore students understand science in different ways. According to Glynn and Duit, students developed their mental models while interpreting science teaching so that their mental models were more and more corresponding to the conceptual models; but students' mental models often contained many misconceptions that could be resistant to change. Reiss and Tunnicliffe (2001) studied students' understanding of their internal structure, and found differences between student's mental models and their expressed models. They also found that the only way to study students' mental models was to elicit how they used the internal models to describe real world situations.

Edwards and Mercer (1995) compared students' spontaneous contributions and contributions influenced by the teacher. They found a great influence by the classroom discourse on students' learning and that individuals in discussions built up joint communication tools. Schoultz, Säljö, and Wyndhamn (2001) also discussed the role of talking with the researcher when studying conceptual knowledge and communication, focusing on differences between talk and text. They carried out an interview study with Swedish seventh graders using paper and pencil questions from the Third International Mathematics and Science Study (TIMSS). They compared knowledge and achievement focusing on differences between written and spoken explanations, and concluded that it is doubtful if the TIMSS items test knowledge of science concepts to any significant extent.

Mortimer (1995) also studied students' use of science knowledge in the classroom discourse. He presented a model for analysing conceptual evolution in the classroom, based on the notion of conceptual profile. He suggested that it is possible to use different ways of thinking in different domains. According to him, learning science is to change a conceptual profile and become conscious of different zones of the profile. Mortimer (1998) developed further his idea when he analysed students' classroom talk during teaching sequences on the particle model of matter. He presented two dimensions of the science classroom - the conceptual and the discursive dimensions. In the conceptual dimension, he found three different zones of conceptual profiles of the concept of matter. The first zone, the 'sensible 
zone' (appealing to the senses), is characterized by the absence of any discontinuous notion of matter. The second zone was called 'substantialist atomism', and students in this category think of particles as grains of matter that e.g. can dilate or change state. The third zone, the 'conceptual zone', is characterized by the classical notion of atoms as basic units of matter'; the atom is a material particle and its behaviour is governed by mechanical laws. Substances are made up of molecules that result from combinations of atoms. Mortimer supported that the student must acquire the concept in a conceptual profile and then he/she must be aware of his/her own profile and its limitations. Another implication is how to find out more about students' conceptual profile before teaching. For this, it is convenient to choose phenomena involving transformations of matter. When discussing the discursive dimension, he found that the construction of knowledge in classrooms seems to depend both on social constrains and on experiences and conclusions from crucial experiments. An analysis focusing on the conceptual dimension says nothing about students' learning in the classroom. Mortimer found that in the science classroom discourse knowledge is both constructed and transmitted in the social setting. The teacher must introduce the discourse of science and help the students to build new meanings.

Research on students' conceptions of science concepts and how they talk about everyday phenomena was important for us when we designed teaching sequences and interviews during our project. Piaget (1972) found a spontaneous development of students' atomism when they talked about dissolving sugar in water. The students said that the visible grains of sugar would be split into smaller and smaller particles until we cannot see them. Novick and Nussbaum (1978) used "magic glasses" to challenge students' models of gases. They meant that students must practice to use and develop their own models. According to de Vos and Verdonk (1996), the particle model of matter is a good example of the conflict between complicated modern theories that are difficult for students to accept, and the use of simplified models that are naive and false. They meant however that it is important for students to work with models. Solomon (1992) and Claxton (1993) stated that students' descriptions of the particle nature of matter often are unconnected and fragmentary.

Many studies have been carried out which address students' conceptions of transformations of matter but very few have a longitudinal design. In many of these studies the researchers conclude that young students could use a basic particle model to explain everyday phenomena (Novak \& Musonda, 1991; Johnson, 1998). Novak's and Mosunda's (1991) conclusions from their twelve-year longitudinal study of science concept learning also implied an early introduction. Nakhleh and Samarapungavan (1999) stated that your imagination helps you to understand the microscopic world. This could be an argument for early presentation of the particle nature of matter because young children like to enter into their imagination when talking about the invisible particles in substances. Andersson (1990) and Johnson (2000a, 2000b) reported on students' difficulties in explaining transformations that involve chemical reactions. Andersson defined a categorisation of students' explanations of situations involving chemical reactions as follows: it is just like that, displacement, modification, transmutation, and chemical interaction. Many researchers have used Andersson's categorisation. Often very few students are found to be in the last category that corresponds to the chemists' understanding of chemical reactions. Krnel, Watson and Glazer (1998) reported that if students did not know the difference between object and substance, they explained chemical reactions as modifications. Johnson (2000a) thought that using Andersson's categories favoured those who had a good concept of matter. You cannot see when a substance changes if you do not know what a substance is. Some researchers have used other tools to study students' conceptions of chemical reactions. Holding (1987) and Meheut and Chomat (1990) found that students often talked about what happens with one of 
the substances and said nothing about interaction between the substances involved in the reaction.

The aim of the present study was to answer the following questions:

- How does a group of 10-year-olds use their 'mental models' of the nature of matter when they talk about everyday phenomena involving transformation of matter?

- How is the development of the students' understanding influenced by the introduction of a basic particle model?

- How does talking with a researcher influence students' use of scientific knowledge?

\section{METHODS AND SAMPLES}

In this project we studied students' tendency to use their knowledge. Students' spontaneous contributions were studied as well as contributions after teachers influenced them. We used an idea from Edwards and Mercer (1995) to define two levels of how students used their knowledge. Students' answers on direct questions from the teacher were called spontaneous contributions. The other level, talking with the researcher(s), was students' answers when we asked follow-up questions. We also related this to Vygotsky's zone of proximal development. Spontaneous answers were those the student could provide on his/her own and could be seen as corresponding to the student's mental age. On the other hand, when the researcher asked follow-up questions to elicit answers, they were considered as answers reached with assistance.

The present study builds upon data from a two-year longitudinal study of 40 students' explanations of everyday phenomena involving transformations of matter. The sample included students in five classes from two different schools, between 10 and 11 years of age. All students were born in the same year. Data were collected in four interviews with each student from age ten to twelve. After an introductory interview, there was one instructional unit of three lessons, followed by an interview two months later within each term. Knowledge of research on students' use of scientific knowledge when talking about everyday phenomena was an important source when we planned the content and implementation of the teaching units and interviews. In this project, the researchers were the teachers as well as the researchers.

In the $1^{\text {st }}$ and the $3^{\text {rd }}$ interview, the same three situations were discussed: a sealed box with soil, a burning paper/a burning candle and the smell of sweets. In the $2^{\text {nd }}$ and $4^{\text {th }}$ interview, other situations such as burning petrol, rusting iron, rain, and magnesium in citric acid were discussed. We used semi-structured clinical interviews. All situations discussed during the interviews were illustrated with real objects. Thus, the burning paper was set on fire during the discussion, while when we discussed smell, we had sweets that smell. We had a list of things to be discussed, but our follow-up questions built upon the students' answers. One aim of the interviews was to present the discourse of science when talking about everyday phenomena.

In the instructional units that were taught in the time between the interviews, some key ideas were presented and the students were doing practical work and discussing in groups of four. In the first instructional unit, a basic particle model was introduced, namely that all substances consist of small particles which we call molecules. Different substances consist of different molecules, while molecules are not static but move around all the time. The particle model was used and improved during the three instructional units. Our purpose was to study how students used this particle model to build up mental models and how they used these models when talking about everyday phenomena. The mental models were challenged during 


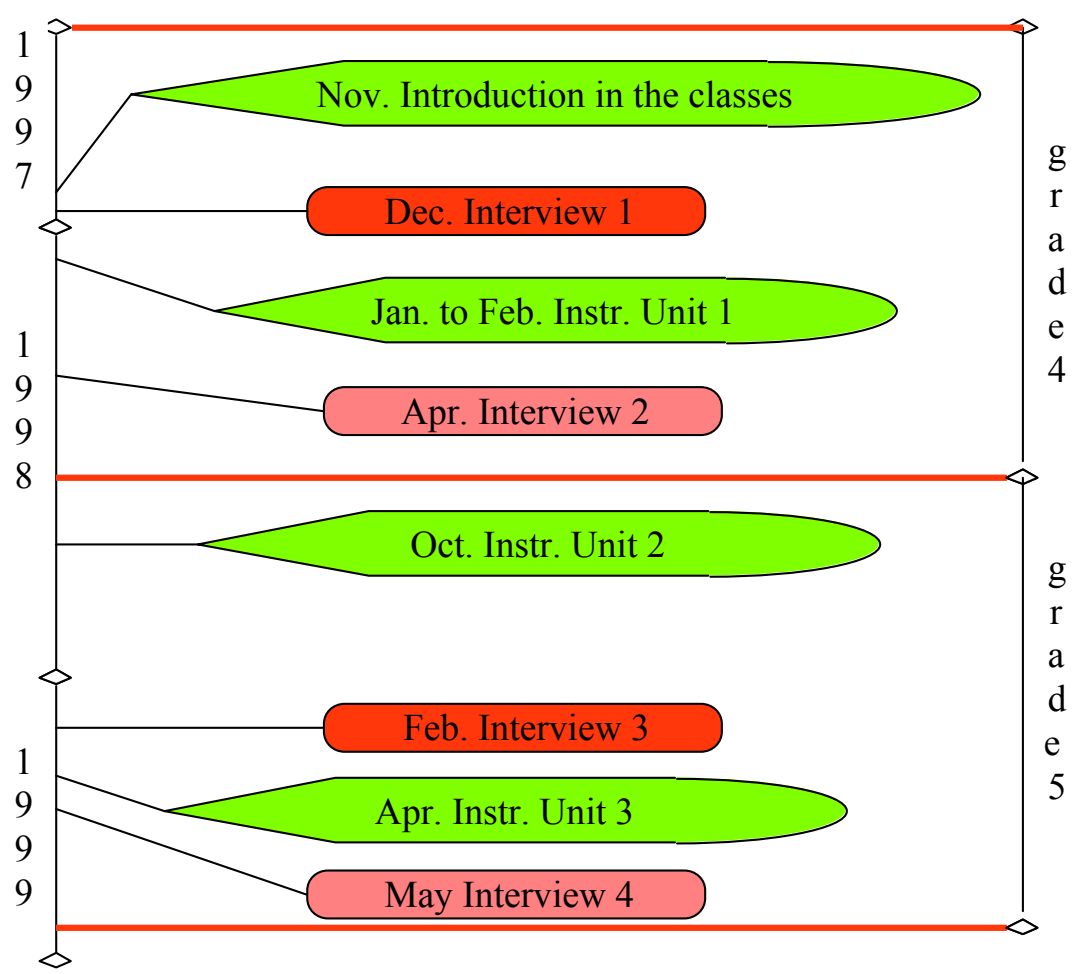

FIGURE 1. Flowchart of the study.

discussions with peers and us. In the interviews, we looked for how students' used their mental models when they explained new situations. We related this to students' conception of the particle model of matter. In addition, we discussed situations not discussed in the instructional units.

All the interviews were tape-recorded and transcribed verbatim. The lessons were videotaped and transcribed. The longitudinal design made it possible to analyse the development of the individuals from different perspectives, e.g. over time, in different contexts, or the influence during the instructional units. Students' conceptions, as shown in the semi-structured interviews, were analysed for their spontaneous explanations as well as for their explanations with appropriate help when discussing with us. A longitudinal study to this extent generated a lot of data. Using computer programs, e.g. NUD*IST (http://www.qsr.com.au/products/n6.html), developed for qualitative analysis, made this work easier. The NUD*IST program assisted us in organising and analysing our qualitative data. We could import and code textual data, edit the text without affecting the coding; retrieve, review and recode coded data; search for combinations of words in the text or patterns in the coding.

In Table 1 we show the categorisation of three parts of an interview. In this example we chose the analysis of how students talk about gases. We did not ask questions about gases, but the students used their knowledge about gases when talking about everyday phenomena.

\section{RESULTS}

The interviews were analysed from different starting-points. The systems of categories were based on students' answers and on the scientific concepts. In each case we tried to find categories corresponding to an increasing quality of understanding. We start with an account of the development of students' particle models and how they used these models. Then we summarize how they talked about gases and situations involving chemical reactions. 
TABLE 1. Categorisation of pupils' statements: Excerpt from the $4^{\text {th }}$ interview with Alma. I= Interviewer

\section{The football}

Alma: The football will be heavier when we blow it up.

I: Can you explain that?

Alma: The air has weight, and when you blow air into the ball, it will be heavier. [gases have weightspontaneously]

\section{The burning petrol}

I: Usually we talk about burning things, and today I will set fire to some petrol. We take some drops of petrol in a cup. Do I have to put a burning match into the petrol or can I hold it over the petrol?

Alma: You can hold it over the petrol. Air is moving around like water and has some steam over the liquid. If you put it into the petrol, the match will burn out. [macroscopic-spontaneously]

I: Will any ashes be formed when petrol is burning?

Alma: I do not know.

I: What will happen if I put a jar over the burning petrol?

Alma: The petrol is burning out. Oxygen from the air is needed, and when it is used up, the petrol will burn out. [macroscopic - spontaneously]

I: Will it burn out at once or step by step?

Alma: Little by little. There is still some oxygen in the jar. [macroscopic-talking with us]

I: I put fire to the petrol and put a jar over the cup. The jar is misted over. Where does it come from?

Alma: From the fire or from the petrol. When it becomes warm it will evaporate. [macroscopic talking with us]

The rain.

I: Tell me about how it will be rain.

Alma: Rivers, lakes and the ground contain water. When it will be warm, steam is formed and the steam rises. [macroscopic - talking with us]

I: Yes..

Alma: And clouds are formed.

I: What will happen in the clouds?

Alma: In the clouds the water molecules are gathered together [molecular, talking with us]

\section{The particle nature of matter}

In the project we used a basic particle model. According to this model all substances consist of small invisible particles called molecules. In the case of water, we have water molecules; in the case of air, we have air molecules. We did not focus on the differences between different molecules, nor we decided to distinguish between atoms and molecules. All molecules in substances move around all the time. The combined categorisation of students' conceptions of the particle nature of matter contained three aspects:

A/ the quality of students' particle model demonstrated during the interviews;

$\mathrm{B} /$ the tendency of students to use their concept of molecule during the interviews;

$\mathrm{C} /$ the number of situations in the interviews where they used the concept of molecule.

The aspect of the quality of students' particle model showed during the interview was based on students' explanations from the "talking with us" perspective. It contained students' spontaneous statements as well as what they said after our follow-up questions. This aspect was categorized in the following categories: recognizing the word molecule, using the word molecule in descriptions, and using the word molecule in explanations. Statements in the explanation category involve talking about molecules as particles. 
Aspect ' $A$ ' in the described categorisation was also used in the case of students' spontaneous explanations. Several students had the highest level in many of the three later interviews on the "talking with us" perspective, but their spontaneous use of the concept came later. Sometimes students were assigned a lower category in a later interview. We think this is because they had parallel models of explanations and that they used the model they thought was best for each situation. When their model with the scientific content is growing stronger, we think they chose this in more different situations.

Students' tendency to use the concept of molecule during the interview was defined as the spontaneity of their use of the concept. The categories were: (i) use after the influence of our follow-up question, (ii) spontaneous use later on in the interview but before our follow-up question, and (iii) spontaneous use early in the interview. Our reason for aspect ' $\mathrm{B}$ ' of students' conceptions was that the use of the concept was related to the quality of the molecule model. If the students had a good particle model and could see the use of it, they would also use it more spontaneously.

Aspect ' $C$ ' in the combined categorisation was the number of situations in the interview where the students used the concept of molecule. If a student could see the use of the molecule model in all three situations discussed in the interview, we think she/he also built it on a model of higher quality (see Table 2).

TABLE 2. Combined categorisation of students' use of their molecule model.

\begin{tabular}{|l|l|l|l|}
\hline Category & The quality & The tendency & Number of situations \\
\hline Do not mention & $\begin{array}{l}\text { Say nothing about } \\
\text { molecules }\end{array}$ & Say nothing about molecules & No situation \\
\hline Stimulated & Know the word & Use the word after stimulation & In at least one situation \\
\hline Spontaneously & Use the word & $\begin{array}{l}\text { Spontaneously later on in the } \\
\text { interviews }\end{array}$ & In at least one situation \\
\hline $\begin{array}{l}\text { Spontaneously } \\
\text { well }\end{array}$ & $\begin{array}{l}\text { Use a particle model in } \\
\text { explanations }\end{array}$ & $\begin{array}{l}\text { Spontaneously in the beginning } \\
\text { of the interviews }\end{array}$ & $\begin{array}{l}\text { In two or more of the } \\
\text { three situations }\end{array}$ \\
\hline
\end{tabular}

The highest combined category, spontaneously well, meant that the students used their concept of molecule to explain phenomena spontaneously in two of the three situations in the interview, and the category spontaneously that they used their concepts of molecule spontaneously in one situation in the interview. The category stimulated contained those students who used their concept of molecule to describe what happened in the situation only after stimulation from the interviewer. The stimulation could be a follow-up question. Students not using the word molecule in their descriptions had the lowest category, do not mention, for the interview. Table 3 illustrates the differences in categorisation in the $2^{\text {nd }}$ and $4^{\text {th }}$ interview.

In Table 3 we compare the categorisation of students' use of their concepts of molecules in the $2^{\text {nd }}$ and $4^{\text {th }}$ interview. Even though students' statements were influenced by the interview situation and situations discussed, we think that this comparison describes the development of the group as well as of individuals. About $50 \%$ of the students belonged to a higher category in the later interview, when comparing the use of their particle model in the second and forth interview. Many of them were in categories two or more steps higher. In the $4^{\text {th }}$ interview twelve students, $30 \%$, used molecules spontaneously to explain the phenomena in more than one context (spontaneously well), and more than $80 \%$ did this spontaneously or after some assistance (spontaneously well, spontaneously and stimulated). In all comparisons between two interviews, the number of students in the higher categories is increasing. Some 
TABLE 3. Combined categorisation of students' use of their concept of molecule. Comparison between categorisation of the $2^{\text {nd }}$ and the $4^{\text {th }}$ interviews.

\begin{tabular}{|c|c|c|c|c|c|c|}
\hline \multirow{7}{*}{ 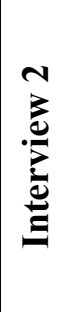 } & & \multicolumn{4}{|c|}{ Interview 4} & \\
\hline & & Do not mention & Stimulated & Spontaneously & Spontaneously well & \\
\hline & Do not mention & 4 & 8 & & 6 & 18 \\
\hline & Stimulated & 3 & 3 & 3 & 1 & 10 \\
\hline & Spontaneously & & 1 & 1 & 3 & 5 \\
\hline & Spontaneously well & & 4 & & 2 & 6 \\
\hline & & 7 & 16 & 4 & 12 & 39 \\
\hline
\end{tabular}

individuals were assigned a lower category in a later interview. Four of them were assigned spontaneously or spontaneously well in the second and the third interview, but in the $4^{\text {th }}$ interview they did not use their particle model spontaneously. This could be due to the fact that this interview did not stimulate those students to use their mental model. In the interviews students adjusted their explanations to the situations discussed. Looking at the whole period, we found that the group as well as the individuals increased the quality of the use of their models to explain everyday phenomena.

In the $4^{\text {th }}$ interview the students were invited to tell us what they knew about molecules. The analysis of these answers was based upon how many of the following three components the students had spontaneously in their answers: 1/ all substances consist of molecules, 2/ the molecules are small, and 3/ different substances consist of different molecules. We compared each student's answer on this question with the combined category for the student. All students in the categories spontaneously well and spontaneously gave two or three of the components. Almost half of the students could mention two or three of the components but they did not discuss the phenomena in a way which placed them in any of the spontaneous categories. They did not see the connection between their concept of molecule and their everyday experiences. Perhaps their models were not suitable to use.

\section{The concept of gases}

When discussing the situations in the interviews, the students often spontaneously talked about gases. This provided information on their knowledge of gases, despite the fact that we did not ask specific questions about gases. In the first teaching sequence, we worked with states of matter and gaseous water. In the second teaching sequence, the students had to describe what a gas is and we carried out experiments comparing compressing air and water. In the third teaching sequence we focused on the weight of air and steam.

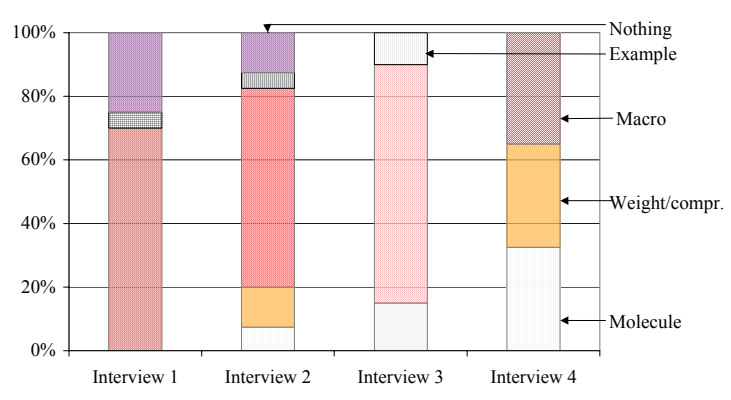

FIGURE 2. Categorisation of students' spontaneous talk about gases.

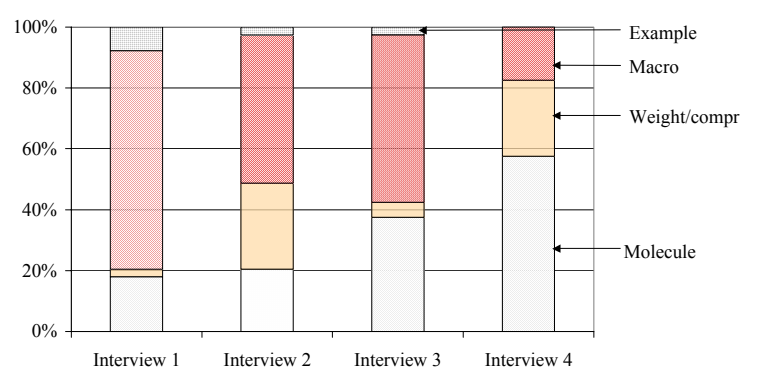

FIGURE 3. Categorisation of students' talk with us about gases. 
The analysis of students' conception of gases had the following categories: comparing with air and other gases; talking about gases on the macro level, e.g. evaporation; giving examples of properties, e.g. a gas has weight or it can be compressed; and talking about gases at the molecular level. Students' talk about gases was analysed from two perspectives: spontaneous talk and talking with us. Many students had a higher level when we asked follow-up questions than in their spontaneous talk. When we were talking about the situations, students left their everyday discourse for a discourse where we used scientific knowledge. Figure 2-3 show the distribution of students' categories for these two perspectives.

The gases that students were talking about were in most cases steam, air and carbon dioxide. Students' talk about gases increased during the project, and they used their knowledge about gases more and more spontaneously. In both perspectives, the higher category students had in the $1^{\text {st }}$ interview the higher category they got in the $4^{\text {th }}$ interview. Students' early experiences of using science when talking about everyday phenomena seemed to stimulate the development of their understanding of science concepts.

\section{The concept of chemical reaction}

Many of the situations discussed during the interviews involved chemical reactions. The concept of chemical reaction was introduced in the last instructional unit. In the previous lessons the students had to describe what happened when they mixed some everyday substances e.g. (i) blueberry mixed with a solution of citric acid, and (ii) a fizzy tablet put in water. In the interviews they met other situations where chemical reactions were involved. Signs of chemical reactions in the descriptions of these situations were studied. The students were not asked to explain the concept of chemical reaction. The categorisation was based on Andersson's (1990) categories: (a) description; (b) a new substance is formed; (c) interaction between substances; and (d) the use of their particle models. The categories new substances are formed and interaction were assigned to statements where students talked about signs of chemical reaction. Interactions means here that at least one of the substances involved exert an influence on the other. Interaction is a higher category than new substances are formed because it means that students' statements contain explanations of what they see happen when new substances are formed. This analysis was based on students' statements in talking with us - not only on what they said spontaneously.

Understanding chemical reactions at the micro level was not the focus of the project. In spite of this, $10-20 \%$ of the students used their molecular models when they talked about chemical reactions. Students' explanations of situations involving chemical reactions seemed, in agreement with our analysis, to be very context dependent. 27 of the 40 students talked about interactions when they talked about the rusting iron, but only three when they talked about the burning paper. When talking about rusting iron, students used verbs as cannot stand, and is corroded. Students' problems explaining burning as interaction have been reported by e.g. Johnson (1997).

The number of students' statements categorised as description, the lowest category, was reduced by $30-40 \%$ when they talked about the same context one year later. Comparing students' explanations on the same or similar situations between the two interviews, we found that for many students there was a higher quality in their explanations in the later interviews. 


\section{Learning situations}

The analysis of the students' conceptions was based on the interviews. In order to illustrate learning situations in the instructional units, we describe two examples: one about gases, and one about chemical reactions.

\section{How heavy is the football?}

In the third instructional unit we used a football to illustrate the weight of gases. We examined what happened to the weight of the football when it was inflated. Students could not have any experiences from everyday life that a football would be one gram heavier when it was inflated. Therefore this example gave us information of the students' conceptions of gases. During the lessons, the students had to tell us what they thought would happen when we carried through the experiment. Some students thought weight would be unchanged because "the air has no weight". Others thought that the ball ought to be lighter. They thought that the ball bounced better, when it was inflated. Four girls in a group told us that they knew that the weight of the football would increase and referred to an experiment with balloons they had seen. When we said that we pumped in as much air as there is in two empty packages for milk, one boy protested. He said that the ball already was full of air and that we could not pump in so much new air. This gave rise to a discussion about compressing air.

When we saw that the football became heavier after inflating it, students tried to explain why. Some of them said that there is more air in it and then it would have more weight. One student used her models of molecules to explain why the ball was heavier. She said that molecules have weight, and after inflating the ball the molecules was closer to each other.

In the $4^{\text {th }}$ interview, the students had to explain why the football became heavier. Almost all of them had explanations that there was more air in it and that air had weight. Some students said that the ball was heavier because the air was more compressed. This could also be interpreted as meaning that the density of the air increased. Some other students said that there would be more molecules in the ball, and therefore it would be heavier.

\section{Chemical reactions}

When studying the results and the conclusions of studies about students' conceptions of chemical reactions, we decided to defer introducing the concept of chemical reaction to the third instructional unit. The chemical reaction was one of the recurrent themes of the study. The first step when we worked with this phenomenon was that students mixed pairs of substances and described what happened. We mostly used everyday substances and reactions involving changes of colour or generation of gases.

The idea that students had to describe signs of chemical reaction and try to explain what happened was followed up in the third instructional unit. Students examined what happened when they put a piece of steel wool in a copper sulphate solution. In addition, using a thermometer, they could notice the raising of the temperature of the aqueous solution as the steel wool and the copper sulphate solution were changing colour. When the students had described what they had seen, we introduced the concept 'react with'. We said that the steel wool had reacted with the copper sulphate. Then the groups had to use this concept when describing if there was a reaction or not when they mixed some new pairs of substances. 
One of these pairs was potassium iodide and lead nitrate. Some potassium iodide and some lead nitrate were put into a beaker containing water. After some minutes, the students saw a yellow line between the two substances. They could not explain how this line built up. Some of them thought that one of the substances became yellow and spread out in the beaker, as Krnel et al (1998) found before. Some students were using their molecular model when talking about what happened. They said that the molecules in the two substances changed places or that when molecules met there would be a yellow substance. There were more students using their molecular model when talking about chemical reactions in some of the experiments than in the interviews. This could be due to the fact that they observed what happened, and in the discussions in the peer group they tested their models. The experiments with bubbles and surprising changes of colours also could contribute to the use of their molecular models.

\section{DISCUSSION AND IMPLICATIONS}

Students used their earlier experiences and the teaching sequences to build up their mental models of e.g. a particle model for matter. When a student talked about everyday phenomena, he/she interpreted the mental model from the specific situation or context. This corresponds to the findings of Reiss and Tunnicliffe (2001) about the differences between students' mental models and their expressed models. In this project we studied students' expressed models.

The students' spontaneous use of their mental models only showed one part of their personal conceptions. When asked follow-up questions, students came to a discourse where one uses his/her knowledge of science when one talks about everyday situations, as Edwards and Mercer (1995) and Schoultz (2001) found. This could be described as students' ability with appropriate help and that they used their zone of proximal development (Vygotsky, 1996). In the same interviews, the students used more or less well-developed particle models. We think that students do not replace their old models; they put for example a new particle model beside their old everyday models. Then they choose which model to use when they meet new situations in the interviews. Students' explanations of lower quality in a later interview were more common in their spontaneous explanations than in the discussions with us. The idea of parallel models of explanations is consistent with the work of Helldén (1998), Marton (1998), Petri and Niedderer (1998), Taber (1998, 2000, 2001), and Tytler (1998), in studies with older students.

The word "chemical reaction" was not used until the last teaching unit. In it, the students had to carry out and to discuss small experiments involving transformations of matter with everyday materials. In connection with this, we discussed what happened at the macro and the micro levels. When analysing students' statements in the interviews, we used levels of categories that could be seen as conceptual profiles. The lowest levels of chemical reaction description could be a sensible profile; a new substance is formed and interaction between substances: a substantialist profile; and the use of their particulate models: a classic notion of atoms as a basic unit of matter (Mortimer, 1995, 1998).

The first research question in this study was: "How does a group of 10-year-olds develop their 'mental models' of the nature of matter?" Only a few students used a mental model of matter containing atoms and molecules when the study began. However, the students showed pre-atomic thinking when we asked them to tell us what they could see if they used magic glasses when they looked into air with steam. Students' descriptions of gases developed and became more and more scientific during the project.

The second research question was: "How is the development of the students" understanding influenced by the introduction of a basic particulate model?" During the 
project more and more students used their particulate model when talking about the situations discussed in the interviews. When they used their model talking about a phenomenon in one of the interviews, they did not always use the model in the other situations discussed in that interview, and they did not always use it in the following interview. Their use of the model seemed in the beginning to be context dependent. Sometimes they used an everyday model of explanation. We used a combined categorisation of students' conceptions of the corpuscular nature of matter containing three aspects to describe students' use of their particle models. Our conclusion from this categorisation is that the quality of students' molecular models was increasing from interview to interview. Some students reached the higher categories already in the second interview, but others did not do so until the fourth interview or not even then. About half of the students had spontaneously well, spontaneously, or stimulated in the fourth interview. This means that they could use their molecular models when discussing known phenomena and that they did it spontaneously or after external influence. We also observed the influence of the introduced particulate model in the analyses of how they talked about gases, phase transitions of water, and chemical reactions. We suppose that the introduced particulate model not only influenced the descriptions at the corpuscular level, but also how they used science knowledge when talking about everyday phenomena at the macroscopic level. We saw examples of this in students' descriptions of what happened when something was burning and of other situations involving chemical reactions.

The third question of research was: "How does talking with us influence their use of scientific knowledge?" Comparisons between students' spontaneous explanations and what they said in dialogue with us were analysed for students' talk about gases and for how they used their concept of molecules. Students had an idea about gases, but only a few of them had a mental model of molecules before the study, and this might have an influence on the results. Students kept their everyday explanations and built up the new mental models in addition to these. Some students seemed to build up their understanding step by step. Students first developed their explanations in dialogue with the researcher, and then in their spontaneous explanations. The two levels 'spontaneously' and 'in dialogue with the researcher' were not two distinct levels. They were two ways to describe students' knowledge. What they said in dialogue with the researcher they also could use spontaneously, but perhaps our questions did not stimulate them to do so or perhaps these models were not so stable to use spontaneously. The changes of discourse in the discussions with us made the students more ready to use knowledge of science when talking about everyday phenomena. We did not encourage them to use this knowledge, but the discussions made them familiar with these ways of arguing and talking.

There are implications of the findings both for teacher education and for teaching science in primary school. In the study students used their imagination when using their mental basic particle models. The use of their mental models was not correct from a science view but in many analyses we found that the students' use of their models became more and more like scientific models. We think that it is possible to introduce very basic models in science education at an early age, and to use students' mental models when talking about gases and everyday phenomena involving transformations of matter.

We only found a few students using particulate models when they talked about phenomena involving chemical reactions. Teaching about chemical reactions should be focused on describing what happens when new substances are formed and the interactions between substances. Even 10-12 year olds were able to develop this understanding of chemical reaction. Students need to meet and discuss new examples in order to build up their own conceptions. In discussions in connection with students' laboratory lessons they meet a discourse where they use scientific knowledge when talking about everyday phenomena. Teachers talking with students about their practical work stimulate them to use more of their 
zone of proximal development. Introducing the concept of conceptual profiles (Mortimer, 1998) could be a useful tool to help students understand the conflict between the scientific models and the simplified models used in science education (de Vos \& Verdonk, 1996).

CORRESPONDENCE: Olle ESKILSSON, Kristianstad University, Department of Mathematics and Natural Sciences, SE-291 88 Kristianstad, Sweden; fax: +46 - 44 - 2034 03; e-mail: Olle.Eskilsson@staff.hkr.se

\section{REFERENCES}

Andersson, B. (1990). Pupils' conceptions of matter and its transformation (age 12-16). Studies in Science Education, 18, 53-85.

Claxton, G. (1993). Minitheories: a preliminary model for learning science. In P. J. Black \& A. Lucas (Eds.), Children's informal ideas in science (pp. 45-61). London: Routledge.

Edwards, D., \& Mercer, N. (1995). Common knowledge. London: Routledge.

de Vos, W., \& Verdonk, A. H. (1996). The particle nature of matter in science education and in science. Journal of Research in Science Teaching, 33, 657-664.

Ernest, P. (1996). Varieties of constructivism: A framework for comparison. In L. P. Steffe \& P. Nesher \& P. Cobb \& G. A. Goldin \& B. Greer (Eds.), Theories of mathematics learning. Mahwah, NJ: Erlbaum.

Glynn, S. M., \& Duit, R. (1995). Learning science meaningfully: Constructing conceptual models. In S. M. Glynn \& R. Duit (Eds.), Learning science in the schools: Research reforming practice, pp. 3-33. Mahwah, New Jersey: Lawrence Erlbaum Associates.

Helldén, G. (1998, April 19-22 1998). A longitudinal study of students' conceptualisation of ecological processes. Paper presented at the Annual Meeting of the National Association for Research in Science Teaching, San Diego.

Holding, B. (1987). Investigation of schoolchildren's understanding of the process of dissolving with special reference to the conservation of matter and the development of atomistic ideas. Leeds: The University of Leeds, School of Education.

Johnson, P. (1997). Why combustion is one of the last things we should expect children to understand. Paper presented to the $4^{\text {th }}$ ECRICE, York, U.K., September 1987.

Johnson, P. (1998). Progression in children's understanding of a basic particle theory: A longitudinal study. International Journal of Science Education, 20, 393-412.

Johnson, P. (2000a). Children's understanding of substances, Part 1: Recognizing chemical change. International Journal of Science Education, 22, 719-737.

Johnson, P. (2000b). Developing student's understanding of chemical change: What should we be teaching. Chemistry Education: Research and Practice in Europe, 1, 77-99. [http://www.uoi.gr/cerp]

Krnel, D., Watson, R., \& Glazar. (1998). Survey of research related to the development of the concept of matter. International Journal of Science Education, 20, 257-289.

Leach, J., \& Scott, P. (2003). Individual and sociocultural views of learning in science education. Science and Education, 12, 91-113.

Marton, F. (1998). Towards a theory of quality in higher education. In B. Dart \& G. Boulton-Lewis (eds.), Teaching and learning in higher education, pp. 177-200. Hawtorn: ACER, cop.

Meheut, M., \& Chomat, A. (1990). The bounds of children's atomism: An attempt to make children build up a particulate model of matter. In P.L Lijnse \& P. P. Licht \& W. d. Vos \& A. J. Waarlo (Eds.), Relating macroscopic phenomena to microscopic particles, pp. 266-282. Utrecht: Centre for Science and Mathematics Education (CD- $\beta$ ).

Mortimer, E. F. (1995). Conceptual change or conceptual profile change. Science and Education, 4, 267-285. 
Mortimer, E. F. (1998). Multivoicedness and univocality in classroom discourse: An example from theory of matter. International Journal of Science Education, 20, 67-82.

Nakhleh, M., \& Samarapungavahn, A. (1999). Elementary school children's beliefs about matter. Journal of Research in Science Teaching, 36, 777-805.

Novak, J. D., \& Musonda, D. (1991). A twelve-year longitudinal study of science concept learning. American Education Research Journal, 28, 117-153.

Novick, S., \& Nussbaum, J. (1978). Junior high school pupils' understanding of the particulate nature of matter: an interview study. Science Education, 62, 273-281.

Petri, J., \& Niedderer, H. (1998). A learning pathway in high-school level quantum atomic physics. International Journal of Science Education, 9, 1075-1088.

Piaget, J. (1972). The principles of genetic epistemology. London: Routledge \& Kegan Paul.

Reiss, M., \& Tunncliffe, S., Dale. (2001). Students' understanding of their internal structure as revealed by drawings. In H. Behrendt \& H. Danche \& R. Duit \& W. Gräber \& M. Kormorek \& A. Kross \& P. Reiska (Eds.), Research in science education - Past, present, and future. Dodrecht: Kluwer Academic Publishers

Schoultz, J., Säljö, R., \& Wyndhamn, J. (2001). Conceptual knowledge in talk and text: What does it take to understand a science question? Instructional Science, 29, 123-236.

Sfard, A. (1998). On two metaphors and the dangerous of choosing just one. Educational Researcher, 27(2), 4-13.

Solomon, J. (1983). Learning about energy: How pupils think in two domains. European Journal of Science Education, 5, 49-59.

Solomon, J. (1992). Getting to know about energy - In school and society: The Falmer Press.

Sutton, C. (1996). Resolving the human voice in science - An urgent problem in school (Working paper): The Leicester Study Groups on School Science after 2000.

Taber, K. S. (1998). An alternative conceptual framework from chemical education. International Journal of Science Education, 20, 597-608.

Taber, K. S (2000). Multiple frameworks? Evidence of manifold conceptions in individual cognitive structure. International Journal of Science Education, 22, 399-417.

Taber, K. S (2001). Shifting sands: A case study of conceptual development as competition between alternative conceptions. International Journal of Science Education, 23, 731-753.

Tytler, R. (1998). The nature of students' informal science conceptions. International Journal of Science Education, 20, 901-927.

Vygotsky, L. S. [ed A. Kozulin (1996)]. Thought and language: MIT Press. (First published in Russian in 1934). 